\title{
Effect of microwave radiation on optical transmission spectra in $\mathrm{SiO}_{2} / \mathrm{SiC}$ structures
}

\author{
Yu.Yu. Bacherikov ${ }^{1}$, R.V. Konakova ${ }^{1}$, E.Yu. Kolyadina ${ }^{1}$, A.N. Kocherov ${ }^{2}$, O.B. Okhrimenko', \\ A.M. Svetlichnyi ${ }^{2}$ \\ ${ }^{1}$ Institute of Semiconductor Physics, NASciences of Ukraine, 45 prospect Nauky, 03028 Kyiv, Ukraine \\ Phone: +38(044) 265 6261; e-mail: olga@isp.kiev.ua \\ 2 Taganrog State Radio Engineering University, 44 Nekrasovskii per., Taganrog GSP-17A, Rostov Region, Russia \\ Phone: +(863-44)6-16-11; e-mail:svetlich@tsure.ru
}

\begin{abstract}
We investigated the effect of microwave radiation on absorption spectra (in $400-800 \mathrm{~nm}$ range) and curvature radius of $\mathrm{SiO}_{2} / \mathrm{SiC}$ structures obtained using traditional thermal oxidation in water vapor at the temperature of $1373 \mathrm{~K}$ and rapid thermal annealing in dry oxygen at $1273 \mathrm{~K}$. From an analysis of the sample optical density and radius of curvature variations with total duration of microwave action, we concluded that the structures obtained using rapid thermal annealing are more stable against microwave action.
\end{abstract}

Keywords: $\mathrm{SiO}_{2} / \mathrm{SiC}$, rapid thermal annealing, traditional thermal oxidation, optical density, microwave action, radius of curvature.

Paper received 03.10.02; accepted for publication 17.12.02.

\section{Introduction}

Presence of localized states in an insulator layer and at insulator/semiconductor interface determines, to a great extent, stability and reliability of devices based on metalinsulator-semiconductor structures. This factor becomes of particular importance for the silicon-carbide-based device structures, because they are intended for operation at higher temperatures than those based on silicon and gallium arsenide. Therefore, search for ways to exert control over the $\mathrm{SiO}_{2} / \mathrm{SiC}$ interface properties is urgent.

In this work we used microwave annealing as a factor acting on the properties of the $\mathrm{SiO}_{2} / \mathrm{SiC}$ interface.

\section{Sample preparation and investigation technique}

We studied the optical transmission spectra and radii of curvature of $\mathrm{SiO}_{2} / \mathrm{SiC}$ structures obtained by oxidation of Lely-grown $n-6 \mathrm{H}-\mathrm{SiC}$. The free electron concentration was $\sim 10^{18} \mathrm{~cm}^{-3}$. The following two techniques were used for silicon carbide oxidation: (i) traditional thermal oxidation in water vapor for 30 to $180 \mathrm{~min}$. at the tem- perature $T=1373 \mathrm{~K}$, and (ii) rapid thermal annealing (RTA) in dry oxygen for 60 to $180 \mathrm{~s}$ at $T=1273 \mathrm{~K}$. The obtained $\mathrm{SiO}_{2} / \mathrm{SiC}$ structures were exposed to repeated microwave annealing in a magnetron processing chamber (frequency $f=2.45 \mathrm{GHz}$, irradiance of $1.5 \mathrm{~W} / \mathrm{cm}^{2}$ ).

The transmission spectra in the $400-800 \mathrm{~nm}$ range were registered with a SDL-2 plant at the room temperature. A spectral lamp SIRSH-200 served as a continuous spectrum source.

\section{Experimental results and discussion}

Table 1 presents radii of curvature $R$ (measured on the (0001) face side) of different $\mathrm{SiO}_{2} / \mathrm{SiC}$ structures as a function of total time of exposure to microwave radiation $t_{\mathrm{T}}$. The structures obtained with traditional thermal oxidation in water vapor at $1373 \mathrm{~K}$ (samples-I) appeared to be more sensitive to microwave radiation; the degree of $R$ changing with $t_{\mathrm{T}}$ is proportional to duration of initial sample oxidation. Contrary to this, for the samples obtained using RTA in dry oxygen at $T=1273 \mathrm{~K}$ (samplesII) the radii of curvature practically did not depend on $t_{\mathrm{T}}$.

A typical dependence of optical density (OD) of $\mathrm{SiO}_{2} /$ $\mathrm{SiC}$ structure (the initial sample) on the wavelength at $T=300 \mathrm{~K}$ is presented in Fig. $1 . \mathrm{SiO}_{2}$ films are transpar- 
Yu.Yu. Bacherikov et al.: Effect of microwave radiation ...

Table 1. Radii of curvature $R$ (measured on the (0001) face side) of different $\mathrm{SiO}_{2} / \mathrm{SiC}$ structures as a function of total time of exposure to microwave radiation $t_{\mathrm{T}}$.

\begin{tabular}{lcc}
\hline \hline Sample preparation and their number & $\begin{array}{c}\text { Total time of exposure } \\
\text { to microwave radiation } t_{\mathrm{T}, ~} \mathrm{~s}\end{array}$ & Radius of curvature $R, \mathrm{~m}$ \\
\hline traditional thermal oxidation for 30 min., \#1 & 0 & 9 \\
& 10 & 9 \\
& 30 & 8 \\
\hline traditional thermal oxidation for 60 min., \#2 & 40 & 8.6 \\
\hline traditional thermal oxidation for 120 min., \#3 & 0 & 1.4 \\
& 10 & 1.2 \\
& 30 & 3.35 \\
& 0 & 1.3 \\
\hline traditional thermal oxidation for 180 min., \#4 & 10 & 4.1 \\
& 30 & 1.4 \\
& 40 & 1.5 \\
& 0 & 1.9 \\
\hline RTA for 60 s, A & 10 & 16.8 \\
& 30 & 14.7 \\
& 40 & 31 \\
& 0 & 8 \\
\hline RTA for $180 \mathrm{~s}$, B & 10 & 0.5 \\
& 30 & 0.6 \\
& 40 & 0.5 \\
& 0 & 0.5 \\
\hline \hline
\end{tabular}

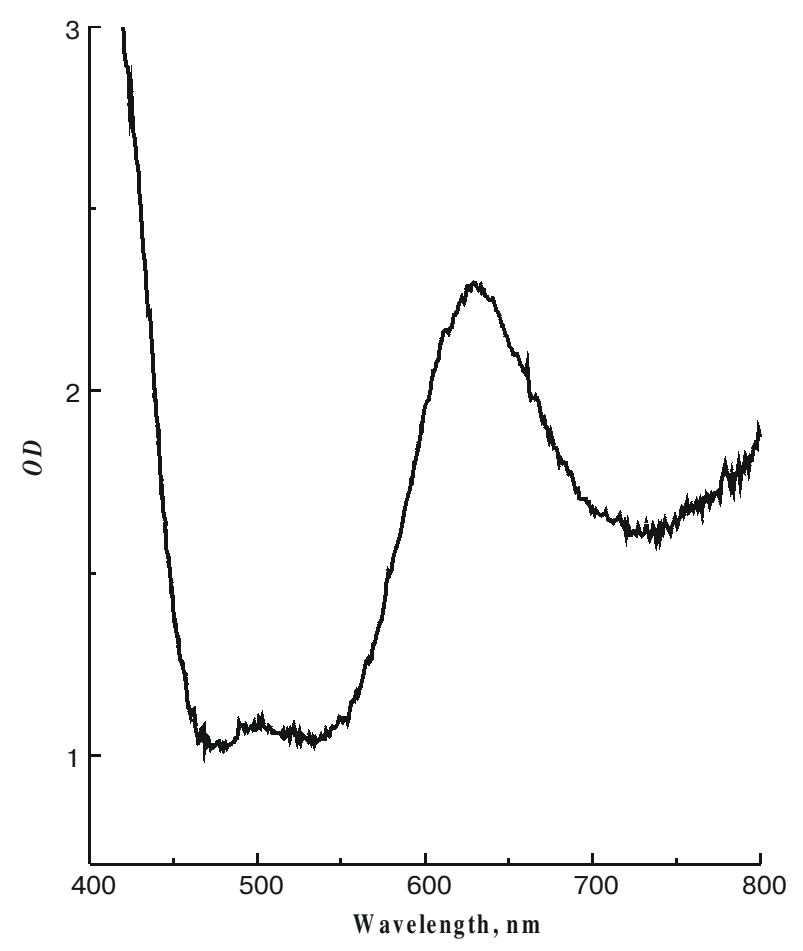

Fig. 1. Typical OD dependence on wavelength for the initial $\mathrm{SiO}_{2} / \mathrm{SiC}$ sample taken at $T=300 \mathrm{~K}$. ent in the 400-800 nm wavelength range. So, the absorption spectrum of $\mathrm{SiO}_{2} / \mathrm{SiC}$ structure is due mainly to absorption in $\mathrm{SiC}$ bulk and at the $\mathrm{SiO}_{2}-\mathrm{SiC}$ interface. An absorption peak observed at $630 \mathrm{~nm}$ (Fig. 1) may be related to the ground state of donor centers resulted from presence of nitrogen impurities in silicon carbide crystals [1-4].

It was found that $\mathrm{SiO}_{2} / \mathrm{SiC}$ demonstrated different dependences of the OD spectra on $t_{\mathrm{T}}$, depending on the technique used for structure oxidation. For the samples$\mathrm{I}$, the OD dependence on $t_{\mathrm{T}}$ is shown in Fig. 2 (for the band with a peak at $630 \mathrm{~nm}$ ). One can see that for all the samples studied the intensity of the above absorption band decreased after exposure to microwave radiation during $10 \mathrm{~s}$. At recurrent microwave action the intensity of the $630 \mathrm{~nm}$ absorption band practically did not change for the samples whose oxidation times were 30,60, and 180 min. (Fig. 2, curves 1, 2, and 4), while for the sample whose oxidation time was $120 \mathrm{~min}$. (Fig. 2, curve 3 ) the absorption band intensity decrease continued.

Next stage of microwave treatment results in increase of the absorption band intensity practically up to the initial value. For the sample whose oxidation time was 120 min. the absorption band intensity after total exposure to microwave radiation for $30 \mathrm{~s}$ becomes even higher than its initial value. Further $t_{\mathrm{T}}$ increase up to $40 \mathrm{~s}$ results in 


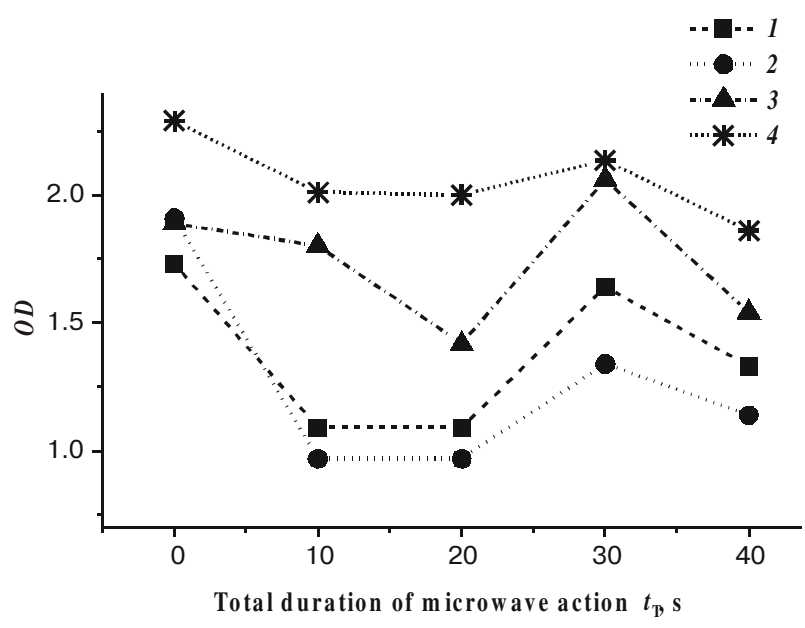

Fig. 2. OD dependence on total duration of microwave action $t_{\mathrm{T}}$ (the $630 \mathrm{~nm}$ absorption band) for the samples-I. Oxidation duration: $1-30$ min., $2-60 \min ., 3-120 \min ., 4-180 \min$.

decrease of the absorption band intensity, which becomes comparable to that after $t_{\mathrm{T}}=20 \mathrm{~s}$. One can see from Fig. 2 that the smallest departure of the absorption band intensity from its initial value is observed in the case when oxidation duration for the $\mathrm{SiO}_{2} / \mathrm{SiC}$ structures-I was $180 \mathrm{~min}$.

The OD dependences (for the $630 \mathrm{~nm}$ band) on total duration of microwave action for the samples-II shown in Fig. 3. One can see that the dependence observed at $t_{\mathrm{T}} \leq 30 \mathrm{~s}$ is similar to that for the samples-I oxidized during 180 min. at $T=1373 \mathrm{~K}$ (Fig. 2, curve 4): a small OD decrease (increase) at total duration of microwave action of 10 and $20 \mathrm{~s}(30 \mathrm{~s})$.

Some distinctions are observed in characteristics of different samples-II at $t_{\mathrm{T}}=40 \mathrm{~s}$. For the sample annealed during $60 \mathrm{~s}$ (Fig. 3, curve A) the intensity of absorption band somewhat drops, while for that annealed during $180 \mathrm{~s} \mathrm{(Fig.} \mathrm{3,} \mathrm{curve} \mathrm{B),} \mathrm{it} \mathrm{is} \mathrm{practically} \mathrm{the} \mathrm{same} \mathrm{as} \mathrm{the}$ initial one.

One can see from Figs 2 and 3 that samples-II demonstrate maximal tolerance for microwave action (Fig. 3, curves A and B). The samples-I, oxidation duration of which was maximal, demonstrate the highest stability against microwave action (Fig. 2, curve 4). It can be seen from their optical transmission spectra.

The dependence of the $630 \mathrm{~nm}$ band half-width on total duration of microwave action is presented in Fig. 4. Contrary to the situation with the same dependence of the band intensity, here one cannot name some trend that would be common for all the samples studied. For the samples-I oxidized during 30 and $60 \mathrm{~min}$. (Fig. 4, curves 1 and 2) the above dependence quantitatively resembles a similar dependence of intensity: first, some decrease of the band half-width with $t_{\mathrm{T}}$ is observed, then it slightly grows, and, at further $t_{\mathrm{T}}$ increase up to $40 \mathrm{~s}$, the band half-width decreases again. For the samples-I oxidized during 120 and $180 \mathrm{~min}$. (Fig. 4, curves 3 and 4), the dependence of the $630 \mathrm{~nm}$ band half-width on total dura-

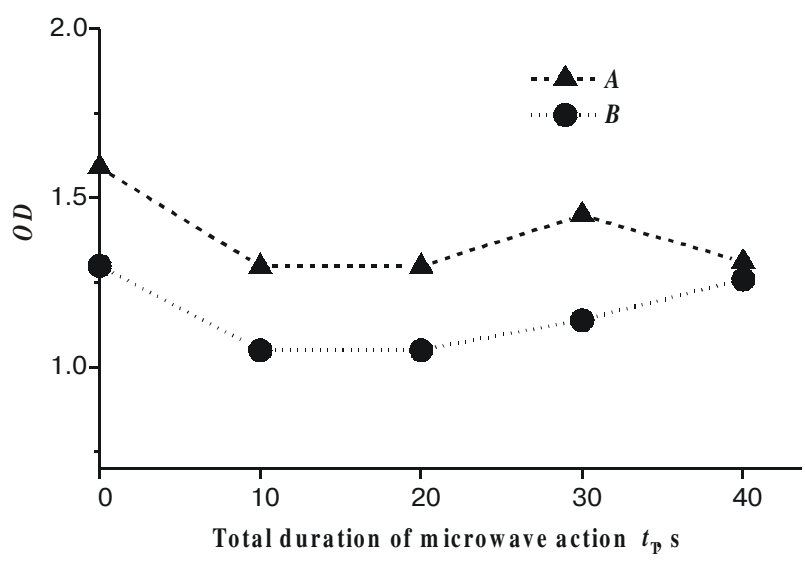

Fig. 3. The same as in Fig. 2 but for the samples-II. Annealing duration: A - $60 \mathrm{~s}, \mathrm{~B}-180 \mathrm{~s}$. (total duration of microwave action $\left.t_{\mathrm{T}}, \mathrm{s}-\mathrm{OD}\right)$

tion of microwave action is somewhat different. When $t_{\mathrm{T}}=10 \mathrm{~s}$, then the band half-width slightly grows; at further $t_{\mathrm{T}}$ increase up to $30 \mathrm{~s}$ it goes down, and at $t_{\mathrm{T}}=40 \mathrm{~s}$ the band half-width slightly increases again. For the samples-II oxidized during $60 \mathrm{~s}$ (Fig. 4, curve A) and $180 \mathrm{~s}$ (Fig. 4, curve B) the above dependence of the band halfwidth is non-monotone.

According to [1-4], the $630 \mathrm{~nm}$ band stems from photoionization of three nonequivalent nitrogen donors nearest neighborhood coordinations of which are hexagonal and cubic. This band actually involves three close bands that merge into a single broad band [4]. Microwave action can lead to fluctuations of nonuniformity of dopants and defects distribution at the structure surface and in the bulk [5]. Variation of nitrogen impurities distribution over the silicon carbide crystal bulk may result in changing the character of inter-impurity interaction

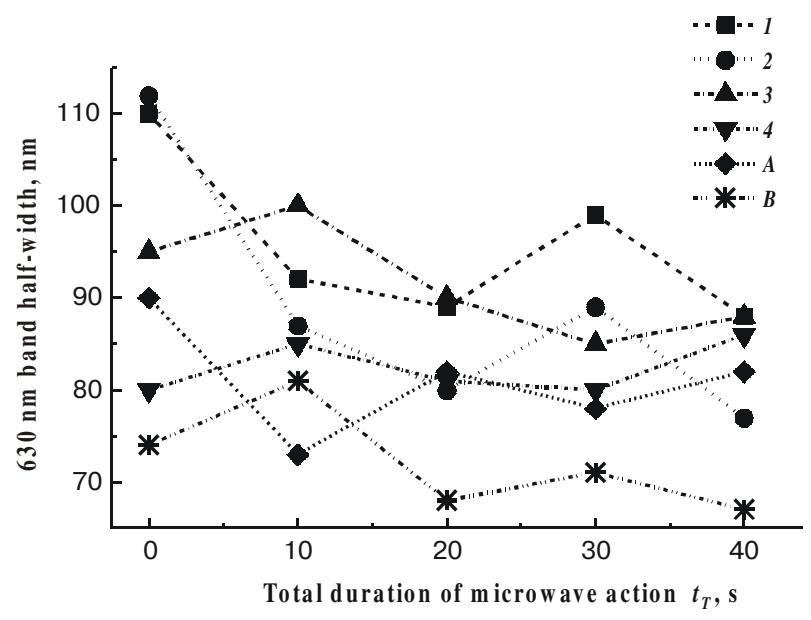

Fig. 4. Dependence of the $630 \mathrm{~nm}$ band half-width on total duration of microwave action $t_{\mathrm{T}} .1-4$ - for structures-I; oxidation duration: $1-30,2-60,3-120,4-180 \mathrm{~min}$. A, B - for structuresII; annealing duration: A $-60, \mathrm{~B}-180 \mathrm{~s}$. 


\section{Yu.Yu. Bacherikov et al.: Effect of microwave radiation ...}

for centers of absorption [6] and, consequently, changing intensity of the observed absorption band. Variation of defects distribution over the sample exposed to microwave radiation can result in changing the absorption band half-width, similarly to the case of the diffraction reflection curves [7]. Besides, (dis)appearance of structural defects under microwave action may be accompanied with changes in symmetry of the nearest neighborhood of single nitrogen atoms thus, resulting in redistribution of intensities of the individual bands that make the $630 \mathrm{~nm}$ band. This, finally, will cause changes in both half-width and intensity of the resulting band.

Presence of three nonequivalent absorption centers enables one to assume that they will demonstrate different degrees of tolerance for microwave action. Nonmonotonic character of the absorption band intensity and half-width dependences on total duration of microwave action may result from redistribution of donors due to their different interactions with microwave radiation. It is believed that most stable against microwave radiation are the samples containing predominantly the donors whose interaction with microwave radiation is the weakest. The character of dependences of the $630 \mathrm{~nm}$ band intensity and half-width on total duration of microwave action evidences that such samples are those obtained using RTA in dry oxygen at $T=1273 \mathrm{~K}$.

\section{Conclusion}

We investigated the effect of microwave radiation on radii of curvature, as well as on intensity and half-width of the $630 \mathrm{~nm}$ band, of the $\mathrm{SiO}_{2} / \mathrm{SiC}$ structures obtained us- ing silicon carbide oxidation in two different ways: (i) traditional thermal oxidation in water vapor at a temperature of $1373 \mathrm{~K}$ and (ii) rapid thermal annealing in dry oxygen at $1273 \mathrm{~K}$. From the experimental results obtained, one can conclude that the structures prepared using technique (ii) are more stable against microwave action.

\section{References}

1. G.B. Dubrovskii, E.I. Radovanova. Optical absorption in the $0.6 \mathrm{~mm}$ region and conduction band structure in a $(6 \mathrm{H})-\mathrm{SiC}$ // Fiz. Tverd. Tela - 1969 - v.11, No 3 - P.680-684 (in Russian).

2. I.S. Gorban, V.P. Zavada, A.S. Skirda. Photoionization spectra of impurity centers in a-SiC $(6 \mathrm{H})$ at high temperatures // Fiz. Tverd. Tela - 1972 - v.14 - P.3095-3097 (in Russian).

3. I.S. Gorban, A.S. Skirda. Absorption spectra of nitrogen impurity in different a-SiC polytypes // Ukrainskii Fiz. Zhurn. 1981 - v.26, No 2 - P.228-232 (in Russian).

4. I.S. Gorban, A.P. Krokhmal. Impurity optical absorption and conduction band structure in $6 \mathrm{H}-\mathrm{SiC} / / \mathrm{Fiz}$. Tekh. Poluprov. - 2001 - v.35, No 11 - P.1299-1305 (in Russian).

5. V.V. Antipin, V.A. Godovitsyn, D.V. Gromov, A.S Kozhevnikov, A.A. Ravaev. Effect of high-power pulsed microwave disturbances on semiconductor devices and integrated microcircuits // Zarubezhnaya Radioelektronika 1995 - No 1 - P.37-53 (in Russian).

6. I.S. Gorban, Yu.A. Marazuev, A.S. Skirda. Impurity absorption spectra of silicon carbide in the near IR region // Fiz. Tverd. Tela - 1972 - v.14, No 3 - P.780-783 (in Russian).

7. L.M. Sorokin, A.S. Tregubova, M.P. Scheglov, A.A. Lebedev, N.S. Savkina. Structural defects in $6 \mathrm{H}-\mathrm{SiC}$ substrates and their effect on epitaxial layer growth by the vacuum sublimation technique // Fiz. Tverd. Tela - $2000-$ v.42, No 8 - P.1384-1388 (in Russian). 